\title{
Levels of anxiety and depression as predictors of mortality following myocardial infarction: A 5-year follow-up
}

\author{
Seyed Hamzeh Hosseini ${ }^{1}$, Ali Ghaemian ${ }^{2}$, Elaheh Mehdizadeh ${ }^{3}$, Haleh Ashraf ${ }^{4}$ \\ ${ }^{1}$ Psychiatry and Behavioral Sciences Research Center, Addiction Institute, \\ Mazandaran University of Medical Sciences, Sari, Iran \\ ${ }^{2}$ Department of Cardiology, School of Medicine, Mazandaran University of Medical Sciences, Sari, Iran \\ ${ }^{3}$ Mazandaran University of Medical Sciences, Sari, Iran \\ ${ }^{4}$ Farzan Clinical Research Institute, Tehran, Iran
}

\begin{abstract}
Background: Post-myocardial infarction (MI) depression is a highly prevalent disorder, affecting nearly $18 \%$ of all MI patients, and it is a major predictor of disability in the year post-MI. We sought to expand this analysis by: comparing case-level anxiety, depression, and comorbid anxiety and depression as predictors of long term mortality during a 5-year follow-up period after MI; and investigating the role of potential modifying and confounding factors.

Methods: A total of 285 patients were screened on average 6 days after their MI and a 5-year survival rate was ascertained. The Beck Depression Inventory (BDI) and the State-Trait Anxiety Inventory (STAI) were completed by patients hospitalized for MI. In addition we tested the BDI $\times$ STAI interaction effect.

Results: During the 5 years of follow-up, cardiac mortality was assessed in 274 of 285 eligible patients. Of the 274 patients whose survival data were available, 91 (33.2\%) died. At entry, BDI score of 192 (67.4\%) patients was $\geq 10$ and 145 (50.9\%) patients had STAI score $\geq 40$. Anxiety was not associated with mortality, whereas depression significantly predicted death, but this association was attenuated to non-significance with full adjustment with disease severity and confounders.
\end{abstract}

Conclusions: Depression following MI does not predict longer-term survival with full adjustment. (Cardiol J 2014; 21, 4: 370-377)

Key words: depression, anxiety, myocardial infarction, mortality

\section{Introduction}

Post-myocardial infarction (MI) depression is a highly prevalent disorder, affecting nearly $18 \%$ of all MI patients [1,2], and it is a major predictor of disability in the year post-MI. Moreover, the question arises whether depression following MI is a risk factor for cardiovascular morbidity and mortality. Although the number of positive studies in this field has been growing steadily, the discrepancies have continued since the publication of a few negative results [3-9]. Scant studies have

Address for correspondence: Seyed Hamzeh Hosseini, MD, Psychiatry and Behavioral Sciences Research Center, Addiction Institute, Mazandaran University of Medical Sciences, Sari, P.O. Box: 13185-1678, Tehran, Iran, tel: +9821 66423101,fax: +982166423304, e-mail: swt_f@yahoo.com 
reported longer-term mortality data in MI patients; whereas one has found an association between an in-hospital depression and mortality 5 years later [10], the other has observed no association at 3 -year follow-up [11]. Although symptoms of depression and anxiety overlap, little is known about how anxiety affects mortality, with reports of both positive and negative effects [12-15].

These apparently conflicting results prompted us to find an answer to the following question: "Is there any association between depression and the cardiovascular mortality following MI"? We had previously found that depression or anxiety would not predict a subsequent increase in mortality during a 24-month follow-up period after MI [8]. We sought to expand this analysis by: comparing case-level anxiety, depression, and comorbid anxiety and depression as predictors of long term mortality during a 5-year follow-up period after MI; and investigating the role of potential modifying and confounding factors.

\section{Methods}

Between 2005 and 2010 all consecutive patients admitted to the coronary care units at Razi Hospital (Mazandaran University of Medical, Ghaemshahr, Iran) and Fatemeh Zahra Hospital (Mazandaran University of Medical, Sari, Iran) who met established criteria for MI were eligible for inclusion in the study. Patients were included if they met World Health Organization criteria for MI during their hospital admission [16]. Patients were excluded from the study if MI was the result of coronary artery bypass graft surgery or angiography, if they had another medical condition likely to lead to death within the next 5 years and if they were unstable medically to complete the assessment even with assistance from the researcher. There were no age or gender restrictions. The study was approved by the ethics committees of the hospitals and was conducted in accordance with Helsinki Declaration.

Patients meeting the inclusion criteria were asked to participate as soon as they were medically stable and had been informed of their diagnosis, on average 6 days after their MI (range 2-15 days). After explaining the study and obtaining written informed consent, a research psychologist (investigator) conducted all baseline interviews which gathered routine demographic data, including age, gender, education, current partner status, history of smoking and alcohol use, history of thrombolytic therapy and any past medical history, including history of cardiovascular disease, diabetes mellitus, hypertension and past psychiatric history. Patients also completed a series of questionnaires. The 21-item self-report Beck Depression Inventory (BDI) whose validity and reliability has been previously approved in Iran $[17,18]$ was used to assess the then current depressive symptoms. Scores of 10 or higher were considered to indicate the presence of mild to severe symptoms of depression [19]. Anxiety was assessed with the Persian version of the Spielberger's State-Trait Anxiety Inventory (STAI). The Persian version of STAI had been used in previous studies and its validity and reliability had been approved [20,21]. The STAI, which comprises two self-report scales, was used to assess state anxiety. Scores of 40 or higher indicated the presence of anxiety symptoms [22].

The main outcome of this study was a 5 -year cardiac mortality. We tested the BDI $\times$ STAI interaction effect in addition to the BDI and STAI main effects. Employing these cut-offs, four groups were identified for the analysis: case-level anxiety only, case-level depression only, case-level comorbid anxiety and depression, and a reference group scoring below case-level on both scales.

\section{Statistical analysis}

Data were analyzed using SPSS for Windows, version 20. All statistical tests were 2-tailed; p values $<0.05$ were considered statistically significant. Categorical variables were compared using the $\chi^{2}$ statistic or Fisher's exact test, if necessary. Continuous variables were compared using independent sample t-tests. The key outcome was cardiac mortality after MI. Cox regression models were used to quantify associations between anxiety, depression and mortality, for investigation of confounding/mediating factors all demographic, clinical, and psychological variables that differentiated patients who died from those who survived were entered into a regression model. The same analyses were constructed for the dichotomized BDI (BDI score $<10$ or $\geq 10$, respectively) and state anxiety scores (dichotomized as $<40$ and $\geq 40$ ).

Results are presented as hazard ratios (HR) with $95 \%$ confidence interval (CI). Individuals still alive at the end of the follow-up comprised a common reference category.

\section{Results}

\section{Participant characteristics}

The mean age of participants was $59.1 \pm 12.03$ years (range 24-85 years) and 197 (69.1\%) were male; 105 (36.8\%) participants were hypertensive, $61(21.4 \%)$ were diabetics, and $77(27.0 \%)$ were 
Table 1. Baseline demographic and psychological data for participants according BDI scores.

\begin{tabular}{|c|c|c|c|c|}
\hline & \multirow[t]{2}{*}{ All patients } & \multicolumn{2}{|c|}{ BDI score } & \multirow[t]{2}{*}{$\mathbf{P}$} \\
\hline & & High $(\geq 10)$ & Low $(<10)$ & \\
\hline Number of subjects & 285 & 192 & 93 & \\
\hline Age [years] & $59.1 \pm 12.0$ & $59.8 \pm 12.3$ & $57.5 \pm 11.4$ & 0.643 \\
\hline Gender (male) & $197(69.1 \%)$ & $120(62.5 \%)$ & $77(82.8 \%)$ & 0.001 \\
\hline Current cigarette smoking & $77(27.0 \%)$ & $43(22.4 \%)$ & $34(36.6 \%)$ & 0.012 \\
\hline Alcohol consumption & $19(6.7 \%)$ & $13(6.8 \%)$ & $6(6.5 \%)$ & 0.919 \\
\hline Marital status*: & & & & 0.474 \\
\hline Single & $2(0.7 \%)$ & $2(1.1 \%)$ & $0(\%)$ & \\
\hline Married & $276(96.8 \%)$ & $184(98.4 \%)$ & $92(100.0 \%)$ & \\
\hline Divorced & $1(0.03 \%)$ & $1(0.5 \%)$ & $0(\%)$ & \\
\hline Education level*: & & & & 0.027 \\
\hline Illiterate & $136(47.7 \%)$ & $104(55.3 \%)$ & $32(35.6 \%)$ & \\
\hline Primary school & $57(20.0 \%)$ & $32(17.0 \%)$ & $25(27.8 \%)$ & \\
\hline Secondary school & $20(70.2 \%)$ & $13(6.9 \%)$ & $7(7.8 \%)$ & \\
\hline Diploma & $46(16.1 \%)$ & $26(13.8 \%)$ & $20(22.2 \%)$ & \\
\hline University degree & $19(6.7 \%)$ & $13(6.9 \%)$ & $6(6.7 \%)$ & \\
\hline Diabetes & $61(21.4 \%)$ & $49(25.5 \%)$ & $12(12.9 \%)$ & 0.015 \\
\hline Hypertension & $105(36.8 \%)$ & $84(43.8 \%)$ & $21(22.6 \%)$ & 0.001 \\
\hline Previous $\mathrm{MI}^{*}$ & $39(13.7 \%)$ & $34(19.7 \%)$ & $5(6.3 \%)$ & 0.007 \\
\hline \multicolumn{5}{|c|}{ Characteristics of index $\mathrm{Ml}$ and its treatment: } \\
\hline Q-wave MI & $97(34.0 \%)$ & $72(37.5 \%)$ & $25(26.9 \%)$ & 0.076 \\
\hline Thrombolysis & $106(37.2 \%)$ & $83(43.2 \%)$ & $23(24.7 \%)$ & 0.002 \\
\hline Past psychiatric history & $13(4.6 \%)$ & $11(5.7 \%)$ & $2(2.2 \%)$ & 0.233 \\
\hline Mean State-Trait Anxiety Inventory & $33.9 \pm 21.2$ & $37.8 \pm 21.2$ & $26.0 \pm 18.9$ & $<0.0001$ \\
\hline
\end{tabular}

*Complete data were not available for this variable; BDI — Beck Depression Inventory; $\mathrm{MI}$ - myocardial infarction

current cigarette smokers; 39 (13.7\%) participants had suffered a previous MI and $105(36.8 \%)$ received thrombolytic therapy.

\section{Baseline characteristics as a function of BDI or STAI status}

Tables 1 and 2 show the baseline demographic, clinical and psychological information for participants with relatively high scores of depression and anxiety compared to those with relatively low scores during their hospital admission after acute MI. At entry, BDI score of $192(67.4 \%)$ patients was $\geq 10$ and $145(50.9 \%)$ cases had STAI score $\geq 40$, respectively.

There were several differences between the groups: those with high BDI scores were more likely to be female, to have hypertension, diabetes or history of a previous MI, less to be current smokers, and to have lower educational level. Anxiety was significantly associated with hypertension and lower educational level. Aside from a substantial association with state anxiety, BDI status was linked only to sex and diabetes in univariate analysis; women and patients with diabetes were more likely to register BDI scores $\geq 10$.

\section{Mortality and depression and anxiety disorders}

Of the 285 completed baseline assessments, 274 were traced on 5 years of follow-up. Of the 274 patients whose survival data were available, $91(33.2 \%)$ died. Non-participants (patients who did not participate in the follow-up) were heterogeneous but did, on average, have poorer health than the participants. Comparison of the 91 dead subjects with the 183 living cases at the time of final assessment has been summarized in Table 3 . Females were more likely to die, and the patients who died during the 5-year follow-up period were significantly older than those who survived, had more history of previous MI, received more thrombolytic therapy in the Index MI and had significantly higher BDI scores.

The data in Table 3 indicate that those who had died had higher BDI scores (depression score) at entry, but STAI score (anxiety score) was not 
Table 2. Baseline demographic and psychological data for participants according STAI scores.

\begin{tabular}{|c|c|c|c|}
\hline & \multicolumn{2}{|c|}{ STAl score } & \multirow[t]{2}{*}{$\mathbf{P}$} \\
\hline & High ( $\geq 40$ ) & Low $(<40)$ & \\
\hline Number of subjects (285) & 145 & 140 & \\
\hline Age [years] & $59.9 \pm 13.1$ & $58.3 \pm 10.8$ & 0.820 \\
\hline Gender (male) & $93(64.1 \%)$ & $104(74.3 \%)$ & 0.064 \\
\hline Current cigarette smoking & $34(23.4 \%)$ & $43(30.7 \%)$ & 0.167 \\
\hline Alcohol consumption & $11(7.6 \%)$ & $8(5.7 \%)$ & 0.527 \\
\hline \multicolumn{4}{|l|}{ Marital status*: } \\
\hline Never married & $1(0.7 \%)$ & $1(0.7 \%)$ & 0.594 \\
\hline Married & $141(99.3 \%)$ & $135(98.5 \%)$ & \\
\hline Divorced/separated/widowed & $0(0.0 \%)$ & $1(0.7 \%)$ & \\
\hline \multicolumn{4}{|l|}{ Education level*: } \\
\hline Illiterate & $82(58.6 \%)$ & $54(39.1 \%)$ & 0.006 \\
\hline Primary school & $21(15.0 \%)$ & $36(26.1 \%)$ & \\
\hline Secondary school & $12(8.6 \%)$ & $8(5.8 \%)$ & \\
\hline Diploma & $19(13.6 \%)$ & $27(19.6 \%)$ & \\
\hline University degree & $6(4.3 \%)$ & $13(9.4 \%)$ & \\
\hline Diabetes & $35(24.1 \%)$ & $27(19.3 \%)$ & 0.321 \\
\hline Hypertension & $67(46.2 \%)$ & $39(27.9 \%)$ & 0.001 \\
\hline Previous $\mathrm{MI}^{*}$ & $23(18.4 \%)$ & $16(12.6 \%)$ & 0.203 \\
\hline \multicolumn{4}{|c|}{ Characteristics of index $\mathrm{MI}$ and its treatment: } \\
\hline Q-wave MI & $39(26.9 \%)$ & $57(40.7 \%)$ & 0.014 \\
\hline Thrombolysis & $60(41.4 \%)$ & $45(32.1 \%)$ & 0.106 \\
\hline Past psychiatric history & $5(3.4 \%)$ & $8(5.7 \%)$ & 0.359 \\
\hline Mean Beck Depression Inventory & $17.8 \pm 10.4$ & $12.2 \pm 10.1$ & $<0.0001$ \\
\hline
\end{tabular}

*Complete data were not available for this variable; MI - myocardial infarction; STAI - State-Trait Anxiety Inventory

different in those who had died and those who survived. However, dichotomized BDI scores also failed to predict mortality at 5 years. Neither state anxiety nor depression scores at entry were different between patients who died from those who survived. Of the 91 patients who died during the 5-year follow-up, 67 (73.6\%) had BDI scores $\geq 10$ and $46(50.5 \%)$ had STAI scores $\geq 40$, while of the 183 survivors, 117 (63.9\%) had BDI scores $\geq 10$ and $90(49.2 \%)$ had STAI scores $\geq 40$ ( $p>0.05$ for each).

After adjustment for age and gender, the associations among BDI score and mortality weakened but remained significant (unadjusted HR 1.032, 95\% CI 1.008-1.057, $\mathrm{p}=0.010$; adjusted HR 1.027, 95\% CI 1.0-1.054). When the relative contribution of all the above mentioned variables singly related to outcome was analyzed by cox regression analysis, older age (HR 1.096, 95\% CI 1.062-1.132, $\mathrm{p}<0.0001$ ), and history of diabetes (HR 2.675, $95 \%$ CI $1.191-6.008, \mathrm{p}=0.017$ ) or previous MI (HR 3.181, 95\% CI 1.329-7.615, p = 0.009) remained significantly and independently associated with mortality; the associations among BDI score and mortality attenuated to a non-significant trend (HR 1.017, 95\% CI 0.987-1.047, p = 0.269).

\section{Analysis of comorbidity}

The diagnoses of depression and anxiety were significantly correlated $(\mathrm{r}=0.269, \mathrm{p}<0.0001)$.

There were $74(27.0 \%)$ cases with only depression and 26 (9.5\%) with only anxiety; 110 (40.1\%) participants had a diagnosis of both depression and anxiety. Percentages of patients who died with both comorbidities, depression only, anxiety only or neither are shown in Figure 1. There was no significant difference between the four study groups in the mortality rate. Simple effect analyses indicated that neither the value of depression for predicting cardiac mortality varied by the severity of comorbid anxiety, nor the value of anxiety for predicting cardiac mortality varied by the severity of comorbid depression. When comorbid with case-level depression, case-level anxiety was associated with a non-significant reduction in mortality (data not shown). 
Table 3. Baseline demographic and psychological data of patients who survived and died during the follow-up.

\begin{tabular}{|c|c|c|c|c|}
\hline & Survivors & Fatalities & $\operatorname{RR}(95 \% \mathrm{CI})$ & $\mathbf{P}$ \\
\hline Number of subjects (274) & 183 & 91 & & \\
\hline Age [years] & $55.9 \pm 11.1$ & $65.9 \pm 11.01$ & $1.083(1.055-1.111)$ & $<0.0001$ \\
\hline \multicolumn{5}{|l|}{ Gender: } \\
\hline Male & $135(73.8 \%)$ & $55(60.4 \%)$ & & \\
\hline Female & $48(26.2 \%)$ & $36(39.6 \%)$ & $1.841(1.079-3.140)$ & 0.025 \\
\hline \multicolumn{5}{|l|}{ Smoking status: } \\
\hline Current smoker & $51(27.9 \%)$ & $21(23.1 \%)$ & $0.776(0.433-1.394)$ & 0.397 \\
\hline Nonsmoker & $132(72.1 \%)$ & $70(76.9 \%)$ & & \\
\hline \multicolumn{5}{|l|}{ Alcohol consumption: } \\
\hline No & $169(92.3 \%)$ & $87(95.6 \%)$ & $1.802(0.576-5.639)$ & 0.312 \\
\hline Yes & $14(7.7 \%)$ & $4(4.4 \%)$ & & \\
\hline \multicolumn{5}{|l|}{ Marital status*: } \\
\hline Never married & $1(1.1 \%)$ & $0(0.0 \%)$ & - & - \\
\hline Married & $88(98.9 \%)$ & $179(100.0 \%)$ & & \\
\hline Divorced/separated/widowed & $0(0.0 \%)$ & $0(0.0 \%)$ & & \\
\hline \multicolumn{5}{|l|}{ Education level*: } \\
\hline Illiterate & $61(67.0 \%)$ & $71(40.3 \%)$ & - & - \\
\hline Primary school & $16(17.6 \%)$ & $37(21.0 \%)$ & & \\
\hline Secondary school & $3(3.3 \%)$ & $17(9.7 \%)$ & & \\
\hline Diploma & $10(11.0 \%)$ & $34(19.3 \%)$ & & \\
\hline University degree & $1(1.1 \%)$ & $17(9.7 \%)$ & & \\
\hline \multicolumn{5}{|l|}{ Diabetes: } \\
\hline No & $153(83.6 \%)$ & $64(70.3 \%)$ & $2.152(1.185-3.906)$ & 0.012 \\
\hline Yes & $30(16.4 \%)$ & $27(29.7 \%)$ & & \\
\hline \multicolumn{5}{|l|}{ Hypertension: } \\
\hline No & $122(66.7 \%)$ & $51(56.0 \%)$ & $1.569(0.937-2.627)$ & 0.087 \\
\hline Yes & $61(33.3 \%)$ & $40(44.0 \%)$ & & \\
\hline \multicolumn{5}{|l|}{ Previous $\mathrm{Ml}^{*}$ : } \\
\hline No & $150(91.5 \%)$ & $57(72.2 \%)$ & $4.135(1.981-8.635)$ & $<0.0001$ \\
\hline Yes & $14(8.5 \%)$ & $22(27.8 \%)$ & & \\
\hline \multicolumn{5}{|l|}{ Thrombolysis: } \\
\hline Not thrombolyzed & $124(67.8 \%)$ & $48(52.7 \%)$ & $1.883(1.125-3.152)$ & 0.016 \\
\hline Thrombolyzed & $59(32.2 \%)$ & $43(47.3 \%)$ & & \\
\hline \multicolumn{5}{|l|}{ Past psychiatric history } \\
\hline No & $173(94.5 \%)$ & $88(96.7 \%)$ & $0.590(0.158-2.198)$ & 0.431 \\
\hline Yes & $10(5.5 \%)$ & $3(3.3 \%)$ & & \\
\hline BDI score (as continuous variable) & $13.7 \pm 9.8$ & $17.3 \pm 11.7$ & $1.032(1.008-1.057)$ & 0.010 \\
\hline \multicolumn{5}{|l|}{ High BDI score $(\geq 10)$ : } \\
\hline No & $66(36.1 \%)$ & $24(26.4 \%)$ & $1.575(0.904-2.744)$ & 0.109 \\
\hline Yes & $117(63.9 \%)$ & $67(73.6 \%)$ & & \\
\hline STAI score (as continuous variable) & $34.3 \pm 19.8$ & $32.6 \pm 23.4$ & $0.996(0.984-1.008)$ & 0.535 \\
\hline \multicolumn{5}{|l|}{ High STAI score $(\geq 40)$ : } \\
\hline No & $93(50.8 \%)$ & $45(49.5 \%)$ & $1.056(0.639-1.747)$ & 0.831 \\
\hline Yes & $90(49.2 \%)$ & $46(50.5 \%)$ & & \\
\hline
\end{tabular}

*Complete date were not available for this variable; All demographic, clinical, and psychological variables that differentiated patients who died from those who survived were entered into a cox regression model; BDI — Beck Depression Inventory; $\mathrm{Cl}$ - confidence interval; $\mathrm{MI}$ - myocardial infarction; RR — relative risk; STAI — State-Trait Anxiety Inventory 


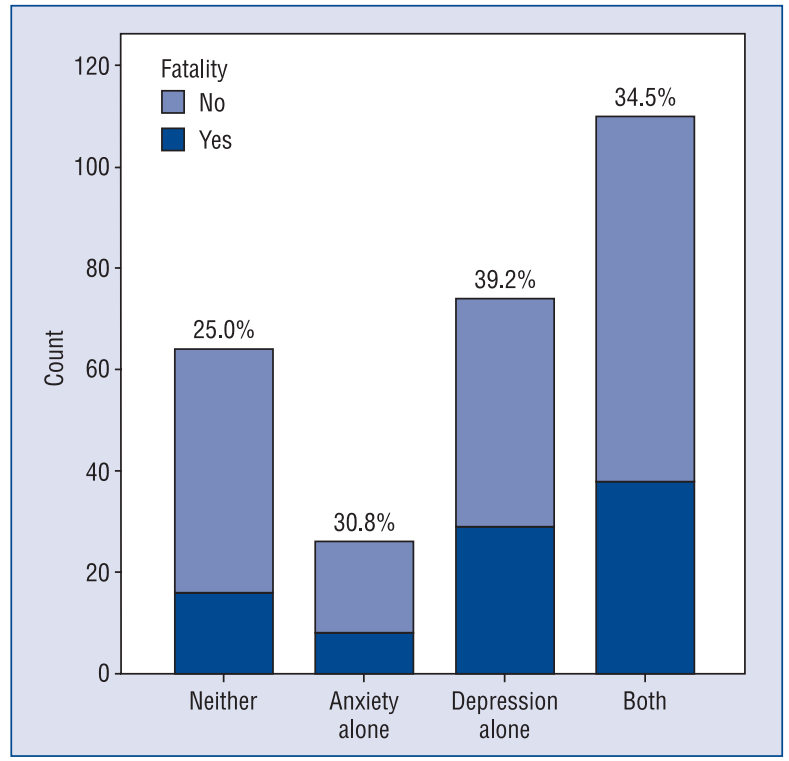

Figure 1. Mortality in each study comorbidity group.

\section{Discussion}

In the present analysis, anxiety was not associated with mortality, whereas depression significantly predicted death, but this association was abolished with full adjustment. Our finding of stronger mortality association in female participants between depression and mortality contrasts with the previously reported stronger effect in men than in women $[23,24]$.

A number of previous studies have evaluated both anxiety and depression disorders and mortality in MI patients. High depression and anxiety values have both been shown to predict subsequent mortality [3, 7]. However, in some cases, symptoms of depression but not anxiety in multivariate models predicted mortality [5, 6], and in some, neither depression nor anxiety symptoms were found to predict mortality in MI patients [9]. Because the studies have varied in location, patient population, sample size, and the means of measuring depression, some variation in results is hardly surprising. In a previous analysis, we found that depression was not a stronger risk factor for post-MI mortality than for other causes combined during a 24-month follow-up [8]. A meta-analysis in 2004 [2] reported that post-MI depression is associated with a 2- to 2.5-fold increased risk of impaired cardiovascular outcome, and a recent meta-analysis in 2013 indicated that, although the association between depression following MI and prognosis is attenuated after adjustment for cardiac disease severity, depression remains independently associated with prognosis with a $22 \%$ increased risk of all-cause mortality and a $13 \%$ increased risk of cardiovascular events per standard deviation in depression $z$-score [25]. The relation of depression with cardiac mortality or all-cause mortality was more significant in the older studies (OR 3.22 before 1992) than in the more recent studies (OR 2.01 after 1992). This is despite the fact that in the recent large-scale intervention trial in MI patients with major or minor depression, the successful treatment of depression was successful in reducing symptoms, however it did not reduce mortality or the recurrence of MI over the average follow-up period of 41 months [26].

It seems more likely that controversies in results of depression and mortality in MI patients hinge on the issue of the relation between depression and disease severity. Depression and anxiety were associated with disease severity in some previous studies showing a relationship between these conditions and post-MI mortality and that disease severity is the underlying cause of death. It is worth noting that in a number of studies in which symptoms of depression were related to both short-term mortality following MI and disease severity, statistical control for disease severity attenuated the significant association between depression and mortality [27-30]. In some previous studies, depression was associated with the severity of cardiac disease. Therefore, the possibility of confounding factors that reduce the strength of the association between post-MI depression and cardiovascular prognosis cannot be fully ruled out. That is why depression and disease severity might be correlated in some studies but not in others; Carroll and Lane [31] have argued that it depends on the accuracy of patients' perceptions of just how serious the event was and the likely prognosis.

The failure of some previous studies with negative results regarding the relationship between depression or anxiety with post-MI mortality, is attributed to the prevalence of mild symptoms among their patients [4, 32]. However, $67.4 \%$ of our patients scored $\geq 10$ on the BDI and $50.9 \%$ scored $\geq 40$ on the STAI, indicating mild to severe symptoms of depression and anxiety, respectively.

Depression and anxiety are highly comorbid psychiatric conditions [33]. In the present study, $40.3 \%$ of total participants had a diagnosis of both depression and anxiety. More strikingly, 59.9\% of those with a diagnosis of depression also had anxiety. The literature on anxiety and mortality is relatively sparse compared to that on depression. 
Previous studies have reported conflicting findings concerning the association between anxiety levels and mortality, which was reported as positive [12], absent [13, 14], and negative [15]. Furthermore, we found lower mortality in participants with comorbid anxiety and depression compared to those with depression alone. The latter finding is contrary to what seems intuitive, since comorbid anxiety and depression are associated with both poorer physical health [34] and more disability [35] than depression alone. We guess that low anxiety may result in reduced asking for help and reduced adherence to medications when somatic illness occurs [36], and may promote earlier identification and treatment of potentially life threatening disease and/or decrease risk behavior associated with non-disease mortality [15]. In other words, there may be an evolutionary benefit of moderate levels of anxiety, a hypothesis that needs further demonstration. These findings of differences between anxiety and depression might be an argument for maintaining the separation of the two disorders. Confounding is also unlikely since there was no apparent alteration following adjustment for the large number of covariates available for this analysis.

\section{Limitations of the study}

It should be conceded that there are a number of limitations to this analysis and its interpretation. First, our patients were hospitalized only for a few days and we did not regard the fluctuating distress reported by patients immediately after an MI as true depressive disorder. Furthermore, patients who were depressed at baseline were less likely to accept follow-up interviews than other patients. However, depression and anxiety at baseline were not related to lack of follow-up, so it is unlikely that the lack of interview data biased the results. To establish a causal relationship, we need longitudinal research combining repeated measurement of depression and its presumed pathophysiological mechanisms, followed by adequately powered, randomized trials targeting the implicated mechanisms.

\section{Conclusions}

In conclusion, the present analysis showed that anxiety symptoms were not associated with mortality, whereas depressive symptoms significantly predicted death, but this association was attenuated to no significance with full adjustment. In spite of non-significant results, with regard to the impact of depression and anxiety on cardiac outcome, it should be stressed that this does not mean that physicians and cardiologists can ignore depression.

\section{Acknowledgements}

This study was supported by a grant from Research Deputy at Mazandaran University of Medical Sciences.

The authors would like to thank Farzan Institute for Research and Technology for technical assistance.

Conflict of interest: none declared

\section{References}

1. Schleifer SJ, Macari-Hinson MM, Coyle DA et al. The nature and course of depression following myocardial infarction. Arch Intern Med, 1989; 149: 1785-1789.

2. van Melle JP, de Jonge P, Spijkerman TA et al. Prognostic association of depression following myocardial infarction with mortality and cardiovascular events: A meta-analysis. Psychosom Med, 2004; 66: 814-822.

3. Denollet J, Brutsaert DL. Personality, disease severity, and the risk of long-term cardiac events in patients with a decreased ejection fraction after myocardial infarction. Circulation, 1998; 97: 167-173.

4. Frasure-Smith N, Lespé rance Depression and anxiety as predictors of 2-year cardiac events in patients with stable coronary artery disease. Arch Gen Psychiatry, 2008; 65: 62-71.

5. Frasure-Smith N, Lesperance F. Depression and other psychological risks following myocardial infarction. Arch Gen Psychiatry, 2003; 60: 627-636.

6. Frasure-Smith N, Lesperance F, Talajic M. The impact of negative emotions on prognosis following myocardial infarction: Is it more than depression? Health Psychol, 1995; 14: 388-398.

7. Herrmann C, Brand-Driehorst S, Kaminsky B, Leibing E, Staats H, Ruger U. Diagnostic groups and depressed mood as predictors of 22-month mortality in medical inpatients. Psychosom Med, 1998; 60: 570-577.

8. Hosseini SH, Yousefnejad K, Tabiban S et al. Effects of depression and anxiety symptoms on cardiac mortality following myocardial infarction: A 2-year follow-up. Int J Psychiatry Clin Pract, 2011; 15: 91-96.

9. Lane D, Carroll D, Ring C, Beevers DG, Lip GY. Mortality and quality of life 12 months after myocardial infarction: Effects of depression and anxiety. Psychosom Med, 2001; 63: 221-230.

10. Lespérance F, Frasure-Smith N, Talajic M, Bourassa MG. Five-year risk of cardiac mortality in relation to initial severity and one-year changes in depression symptoms after myocardial infarction. Circulation, 2002; 105: 1049-1053.

11. Lane D, Carroll D, Ring C, Beevers DG, Lip GY. In-hospital symptoms of depression do not predict mortality 3 years after myocardial infarction. Int J Epidemiol, 2002; 31: 1179-1182.

12. Grasbeck A, Rorsman B, Hagnell O, Isberg PE. Mortality of anxiety syndromes in a normal population: The Lundby study. Neuropsychobiology, 1996; 33: 118-126.

13. Holwerda TJ, Schoevers RA, Dekker J, Deeg DJH, Jonker C, Beekman ATF. The relationship between generalized anxiety disorder, depression and mortality in old age. Int J Geriatr Psychiatry, 2007; 22: 241-249. 
14. Lavretsky H, Mistry R, Bastani R et al. Symptoms of depression and anxiety predict mortality in elderly veterans enrolled in the UPBEAT program. Int J Geriatr Psychiatry, 2003; 18: 183-184.

15. Lee WE, Wadsworth ME, Hotopf M. The protective role of trait anxiety: A longitudinal cohort study. Psychol Med, 2006; 36: 345-351.

16. World Health Organization. WHO MONICA manual. World Health Organization, Geneva 1996.

17. Beck AT, Ward CH, Mendelson M, Mock J, Erbaugh J. An inventory for measuring depression. Arch Gen Psychiatry, 1961; 4: 561-571.

18. Ghassemzadeh H, Mojtabai R, Karamghadiri N, Ebrahimkhani N. Psychometric properties of a Persian-language version of the Beck Depression Inventory; second edition. BDI-II-PERSIAN. Depress Anxiety, 2005; 21: 185-192.

19. Lespé rance F, Frasure-Smith N, Talajic M, Cameron O. Major depression before and after myocardial infarction: Its nature and consequences. Psychosom Med, 1996; 58: 99-112.

20. Bastani F, Hidarnia A, Kazemnejad A, Vafaei M, Kashanian M. A randomized controlled trial of the effects of applied relaxation training on reducing anxiety and perceived stress in pregnant women. J Midwifery Womens Health, 2005; 50: e36-e40.

21. Dadsetan P, Mansour M. Mental illness. Roshd Press, Tehran 1998 [in Persian].

22. Spielberger CD, Gorsuch RL, Luschene RE. Manual for the State-Trait Anxiety Inventory. Consulting Psychologists Press, Palo Alto, CA 1970.

23. Schoevers RA, Geerlings MI, Beekman ATF et al. Association of depression and gender with mortality in old age. Results from the Amsterdam Study of the Elderly (AMSTEL). Br J Psychiatry, 2000; 177: 336-342.

24. Holwerda TJ, Schoevers RA, Dekker J, Deeg DJH, Jonker C, Beekman ATF. The relationship between generalized anxiety disorder, depression and mortality in old age. Int J Geriatr Psychiatry, 2007; 22: 241-249.

25. Meijer A, Conradi HJ, Bos EH et al. Adjusted prognostic association of depression following myocardial infarction with mortality and cardiovascular events: Individual patient data meta-analysis. Br J Psychiatry, 2013; 203: 90-102.
26. Louis AA, Manousos IR, Coletta AP, Clark AL, Cleland JGF. Clinical trials update: The Heart Protection Study, IONA, ACUTE, ALIVE, MADIT II and REMATCH. Eur J Heart Failure, 2002; 4: 111-116.

27. Frasure-Smith N, Lespérance F, Talajic M. Depression and 18-month prognosis after myocardial infarction. Circulation, 1995; 91: 999-1005.

28. Frasure-Smith N, Lespérance F, Talajic M. The impact of negative emotions on prognosis following myocardial infarction: Is it more than depression? Health Psychol, 1995; 14: 388-398.

29. Irvine J, Basinski A, Baker B et al. Depression and risk of sudden cardiac death after acute myocardial infarction: Testing for the confounding effects of fatigue. Psychosom Med, 1999; 61: 729-737.

30. Ladwig KH, Lehmacher W, Roth R, Briethardt G, Budde T, Borggrefe M. Factors which provoke post-infarction depression: Results from the Post-Infarction Late Potential Study (PILP). J Psychosom Res, 1992; 36: 723-729.

31. Carroll D, Lane D. Depression and mortality following myocardial infarction: The issue of disease severity. Epidemiologia e Psichiatria Sociale, 2002; 11: 65-68.

32. Frasure-Smith N, Lespé rance F, Talajic M. Depression following myocardial infarction: Impact on 6-month survival. J Am Med Assoc, 1993; 270: 1819-1825.

33. Panthee B, Kritpracha C. Review: Anxiety and quality of life in patients with myocardial infarction. Nurse Media J Nursing, 2011; 1: 105-115.

34. Stordal E, Bjelland I, Dahl AA, Mykletun A. Anxiety and depression in individuals with somatic health problems. The Nord-Trondelag Health Study (HUNT). Scand J Prim Health Care, 2003; 21: 136-141.

35. Mykletun A, Overland S, Dahl AA et al. A population-based cohort study of the effect of common mental disorders on disability pension awards. Am J Psychiatry, 2006; 163: 1412-1418.

36. Carney RM, Freedland KE, Miller GE, Jaffe AS. Depression as a risk factor for cardiac mortality and morbidity: A review of potential mechanisms. J Psychosom Res, 2002; 53: 897-902. 